\title{
The Health-Care System Issues and Prospects in the Russian Federation
}

\author{
Nikolay Nikolaevich Kalmikov*, Natalia Vasilevna Rekhtina \\ Federal State Educational Institution of Higher Education, Russian Presidential Academy of National Economy and Public Administration (RANEPA), \\ 82 Vernadsky Prospect, 119571 Moscow, Russia \\ *Corresponding author: Kalmikov NN, Federal State Educational Institution of Higher Education, Russian Presidential Academy of National Economy and Public \\ Administration (RANEPA), 82 Vernadsky Prospect, 119571 Moscow, Russia; E-mail: kalmykovnn@kalmykovnn.ru
}

Received: Dec 14, 2015; Accepted: May 24, 2016; Published: May 25, 2016

Copyright: ( 2016 Kalmikov et al. This is an open-access article distributed under the terms of the Creative Commons Attribution License, which permits unrestricted use distribution, and reproduction in any medium, provided the original author and source are credited.

\begin{abstract}
The article involves an analysis of key health-care issues and considers external challenges for the health-care system in Russia until 2020, which should be taken into account while working out and implementing policy decisions in the area of long-term development of the health-care system in the Russian Federation. Priority areas and solutions to major problems are proposed in addition to prospects for medicine development aimed at futher planning of the "The health-care development" program. The article also analyzed the data collected from a survey by interviewing 143 experts. The main research method is an empirical analysis based on the online survey of experts in public administration and policy making.
\end{abstract}

Keywords: Health-care development program; Health-care issues; Solutions to health problems; Opinion survey; Experts

\section{Introduction}

The state of the population health is the most important prerequisite for national prosperity and well-being. Investments into human capital not only have an impact on economic development but are also characterized by high profitability and objective necessity [1]. Taking the above into account, the national policy priorities have began shifting gradually from technical production, which was vital in the past, to education and health care in the course of development and implementation of the "Concept of the Long-Term Social and Economic Development of the Russian Federation until 2020."

This decision was preceded by a hard transition period characterized by the conversion of the old health-care model and worsening of the demographic situation in the country. According to modern research, the population of Russia naturally declined approximately by $13,100,000$ people from 1992 to 2010 (Note 1).

One of the reasons for this situation is that the whole generation was brought up as public service consumers, and the national healthcare system was responsible for the population health. Currently, government measures are aimed at the prevention of demographic crisis consequences, particularly for the public health-care system.

Traditionally, health care in our country was determined as a set of public, social, economic, and medical measures to protect and improve public health. Today, the situation is changing-health care is believed to be a complex system of social and economic relationships and a specific sector of the economy. Moreover, the government's interest in national health is growing and getting structurally complicated.

The Russian Federation program "The health-care development," No. 294 of 2014-04-15, approved by the Russian Federation Government (hereinafter, the Program), is considered one of the main instruments to ensure affordable health care and improved health services, which should in their scope, kinds, and quality correspond to the population morbidity rate and the needs and achievements of medicine.
The program consists of ten tasks and eleven solving subprograms. All tasks can be combined into listed tasks of several general directions:

To improve the efficiency of existing services (to provide priority for preventive health care and primary health-care development, to improve the efficiency of high-tech medical and ambulance services, to improve obstetric and child welfare services, to improve the efficiency and transparency of regulatory functions in public health, to develop population rehabilitation spheres and spa treatment systems);

To introduce and to develop innovations in existing structures (to develop and to implement innovative methods for diagnosis, prevention, and treatment in personalized medicine, to provide palliative care to patients with incurable diseases);

To settle the problem of lack of personnel and resources (to provide the health-care system with highly qualified and motivated personnel, to ensure systematic industry development).

Today, in the Russian Federation health system, in spite of some achievements of previous years, there are problems to be solved for improved population health, increased care affordability, and quality.

The Expert Analytical Center of the Russian Presidential Academy of National Economy and Public Administration conducted this study in the framework of the general discussion of the situation, challenges, and opportunities for the health-care system development in the Russian Federation [15].

The purpose of this study was to obtain experts' assessment of the Russian Federation health-care system and its development problems and prospects. To collect survey data, an online opinion poll [16] was conducted that involved strictly selected experts (Note 2). Data quality control was provided by some special measures.

According to experts (Note 3), the main problems include the following (Figure 1):

1. Personnel issues in the health system, such as lack of qualified specialists (13.0\%), problems in human resources policy (salary level, working conditions) (11.0\%), and poor-quality and degraded training of new staff $(10.4 \%)$

2. Reduced influence and control of modern politics (17.5\%) 
Citation: Kalmikov NN, Rekhtina NV (2016) The Health-Care System Issues and Prospects in the Russian Federation. Biol Med (Aligarh) 8(4): 301. doi:10.4172/0974-8369.1000301.

Page 2 of 6

\section{Lack of adequate funding for the health-care system (11.7\%)}

These issues are specified in the Program, and their solutions are fixed in subprograms. Let's consider the situation in Russia regarding these problematic aspects.

1. The health system funding: Any health-care system is evaluated by health and demographic indicators, including life expectancy (LE) and crude death rate (CDR). For a comparative analysis of birth, mortality, morbidity rates, nonuniform by age and sex groups, standardized death rates are used (SDR) (Notes 4 and 6). We consider it important in this article to analyze the impact of public expenses on the health-care system and population health, so we will use the CDR value.

Figure 2 shows the dynamics of the crude mortality rate in Russia from 1980 to 2011 and forecasts until 2020. The implementation of the priority national project "Health" in 2005-2008 and certain improvement of the social and economic situation in Russia reduced the CDR (Note 5) value by $9 \%$ (from 16.1 to 14.6), which saved lives of 450 thousand citizens in our country. Even a small annual investment in the project ( $10 \%$ of total government expenditures on health care) for 4 years caused positive changes in the population health state [17]. The CDR value remained practically unchanged between 2008 and 2010; the decline was only $3 \%(14.6,2008 ; 14.2,2009 ; 14.2,2010)$. In 2011 , public expenditures on health care were increased by $14 \%$ (or 220 billion rubles per year due to a $2 \%$ increase in insurance premiums by

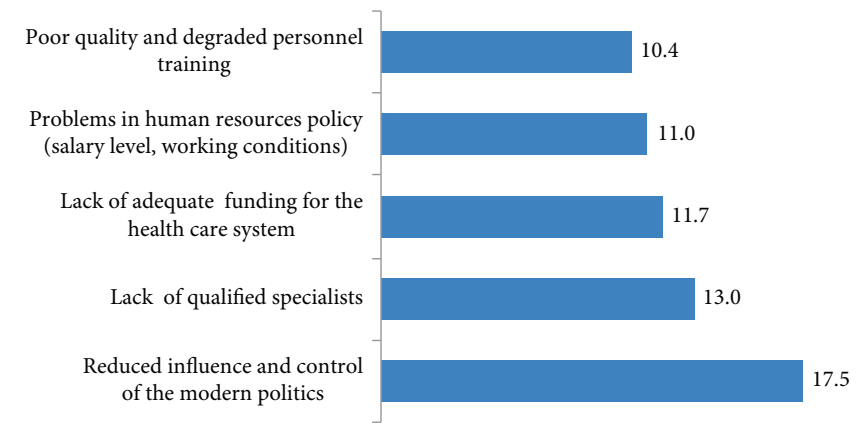

Figure 1: Important problems of health-care development in the Russian Federation, \%

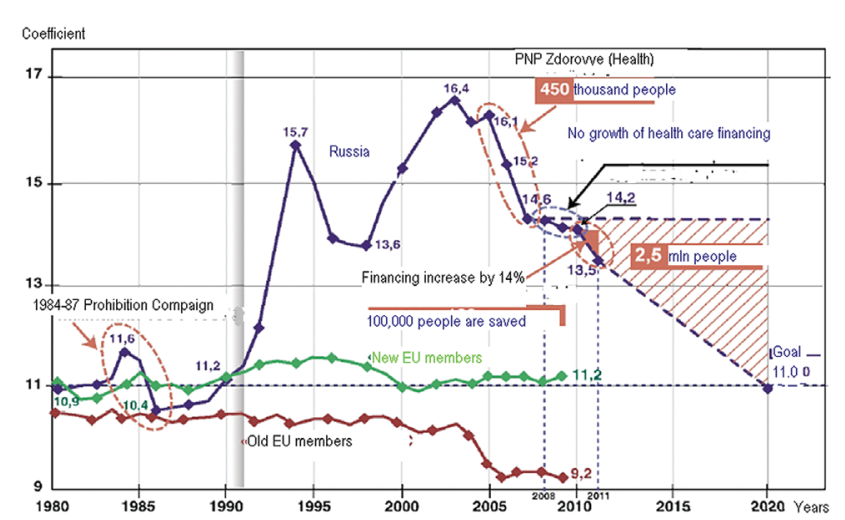

Figure 2: CDR dynamics in "old" and "new" EU members and Russia, CDR prognosis in Russia until 2020
$2 \%$ into the compulsory health insurance system), the mortality rate decreased by 100,000 people, and CDR decreased by $5 \%$ (from 14.2 to 13.5) in 2011 versus 2010.

The CDR indicator is also shown-11.0. It is taken as a target in the Concept of Long-Term Social and Economic Development of the Russian Federation until 2020. By reducing CDR to the level of 11.0, 2.5 million lives will be saved by 2020 . However, it requires much more intensive development of the health-care system.

GDP forecast and expenditures on health care can be given in accordance with the actual Rosstat data for 2005-2010 and forecast provided in Appendix No.1 to the Concept of the Long-Term Social and Economic Development of the Russian Federation until 2020 approved by RF Government order No.1662-p of November 17, 2008 (Table 1) [18].

Table 1 shows increased life expectancy in Russia by 7.8 years in 15 years; under the most optimistic forecast, the growth rate is $112 \%$. During the same period, the gross domestic product is expected to increase from 21.6 to 94.6 trillion rubles (growth rate is $437.6 \%$ ), and health care expenditures are expected to increase from 0.797 to 5.8 trillion rubles, or by $735.6 \%$.

In spite of the expected increase in GDP and expenses on health care, a poor growth of life expectancy at birth is forecasted with very moderate, almost linear-chain increment. A similar trend is shown by the analysis of statistical series of birth and mortality in Russia (see Figure 3) [2].

On the bases of the United Nations, the World Health Organization, and the World Bank, the US-based company providing global business and financial information, Bloomberg [3], introduced the ranking of countries by their health systems effectiveness in 2014. Bloomberg annual ranking of the national health system effectiveness put Russia to the last-51st place (1st place-Singapore, Germany-23th, Azerbaydzhan-49th). Criteria for public health evaluation are as follows: life expectancy, expenditures on health care per capita, the impact of health-care expenditures on the country's GDP ratio. Let's

\begin{tabular}{|c|c|c|c|c|c|c|}
\hline \multirow[b]{2}{*}{ Year } & \multicolumn{4}{|c|}{ Life expectancy (LE) at birth, both genders } & \multicolumn{2}{|c|}{ Financial indicators } \\
\hline & $\begin{array}{c}\text { Life } \\
\text { expectancy } \\
\text { (years) }\end{array}$ & $\begin{array}{c}\text { Absolute } \\
\text { chain } \\
\text { increment }\end{array}$ & $\begin{array}{l}\text { Absolute } \\
\text { base } \\
\text { increment }\end{array}$ & $\begin{array}{l}\text { Chain } \\
\text { growth } \\
\text { rate }\end{array}$ & $\begin{array}{c}\text { GDP } \\
\text { (billion } \\
\text { rubles) }\end{array}$ & $\begin{array}{l}\text { Expenditures } \\
\text { on health } \\
\text { (billion rubles) }\end{array}$ \\
\hline 2005 & 65.3 & & & & $21,609.8$ & 797.1 \\
\hline 2006 & 66.6 & 1.3 & 1.3 & 102.0 & $26,917.2$ & 962.2 \\
\hline 2007 & 67.51 & 0.91 & 2.21 & 101.4 & $33,247.5$ & $1,381.5$ \\
\hline 2008 & 67.88 & 0.37 & 2.58 & 100.5 & $41,277.0$ & $1,546.3$ \\
\hline 2009 & 68.67 & 0.79 & 3.37 & 101.2 & $38,786.0$ & $1,653.0$ \\
\hline 2010 & 68.98 & 0.31 & 3.68 & 100.5 & $44,939.0$ & $1,708.8$ \\
\hline 2011 & 70.3 & 1.32 & 5.0 & 101.9 & $54,369.1$ & $2,990.3$ \\
\hline 2012 & 70.5 & 0.2 & 5.2 & 100.3 & $57,848.7$ & $3,181.6$ \\
\hline 2013 & 70.8 & 0.3 & 5.5 & 100.4 & $61,551.0$ & $3,385.3$ \\
\hline 2014 & 71.2 & 0.4 & 5.9 & 100.6 & $65,490.3$ & $3,602.0$ \\
\hline 2015 & 71.5 & 0.3 & 6.2 & 100.4 & $69,681.6$ & $3,832.5$ \\
\hline 2016 & 71.9 & 0.4 & 6.6 & 100.5 & $74,071.6$ & $4,592.4$ \\
\hline 2017 & 72.2 & 0.3 & 6.9 & 100.4 & $78,738.1$ & $4,881.7$ \\
\hline 2018 & 72.5 & 0.3 & 7.2 & 100.4 & $83,698.6$ & $5,189.3$ \\
\hline 2019 & 72.8 & 0.3 & 7.5 & 100.4 & $88,971.6$ & $5,516.2$ \\
\hline 2020 & 73.1 & 0.3 & 7.8 & 100.4 & $94,576.8$ & $5,863.7$ \\
\hline
\end{tabular}

Table 1: Life expectancy at birth and the main financial values until 2020 


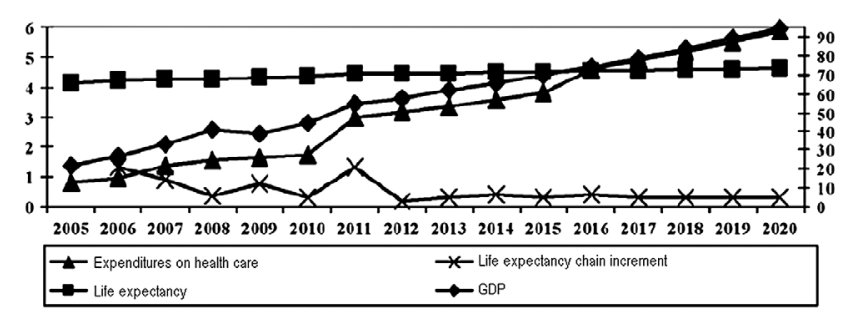

Figure 3: Evolution of life expectancy at birth and key financial indicators

\begin{tabular}{|c|c|c|c|c|}
\hline \multirow{2}{*}{$\begin{array}{c}\text { Rating } \\
\text { position } \\
\text { (among } 51 \\
\text { countries) }\end{array}$} & \multirow[b]{2}{*}{ Country } & \multicolumn{3}{|c|}{ Indicators } \\
\hline & & $\begin{array}{c}\text { Life } \\
\text { expectancy } \\
\text { (years) }\end{array}$ & $\begin{array}{l}\text { Health care } \\
\text { expenditure } \\
\text { to GDP }(\%)\end{array}$ & $\begin{array}{l}\text { Expenditures } \\
\text { on health care } \\
\text { per capita (\$) }\end{array}$ \\
\hline 1 & Singapore & 82.1 & 4.5 & 2,624 \\
\hline 3 & Italy & 82.9 & 9 & 3,032 \\
\hline 23 & Germany & 80.9 & 11.0 & 4,683 \\
\hline 44 & $\begin{array}{l}\text { United } \\
\text { States }\end{array}$ & 78.7 & 17.2 & 8,895 \\
\hline 51 & Russia & 70.5 & 6.3 & 887 \\
\hline
\end{tabular}

Table 2: Indicators of the national health system effectiveness

compare several countries Singapore, Italy, Germany, Russia and the United States, with Singapore in the lead (Table 2).

No doubt, life expectancy is the dominant indicator of the health system effectiveness in any country in the above rating. According to the table, it is clear that today the Russian health-care system can be described as lagging and catching-up compared with the developed countries.

We can see that life expectancy in the United States is higher than in Russia by 8.2 years, and expenditures per capita are more than 10 times higher. However, if we compare the United States to Italy with life expectancy 4.2 years longer, and expenditures per capita almost three times less, it is evident that the health system funding cannot absolutely guarantee a significant increase in life expectancy. Today, in experts' opinion, the US health-care system is one of the most expensive but least effective in the developed world [4,5]. American expert Robert Hanson states that a significant part of health-care costs in the United States fails to provide an expected return. According to him, the United States could cut costs by up to $50 \%$ without reducing the medical care effectiveness [6].

To solve this problem in the health system in Russia, we propose development of the following priority directions [2]:

1. Modernization of primary care and its outpatient care. According to I. M. Sheiman and S. V. Shishkin, additional investment in this sector should be at least 3 times higher than the expenditure on high-tech aid. Only by bringing order to this field, we can solve other issues of national health care system, and it will take at least 4-5 years, according to scientists [7].

2. Simplified financing instruments with a reduced number of financial flows in the medical industry: transition to single-channel financing principles and creation on this bases a full rate for medical services.

3. Maximum use of financial and economic management methods focused upon motivation to improve the system subjects' efficiency. This problem can be solved by improved mechanisms of payment for medical services and for medical personnel's work, which will create incentives for structural reforms, improved service quality, increased prophylaxis, etc. It means advanced and deferred payment methods, with priority given to per capita financing and gradual introduction of fundholding.

4. Elimination of unequal scope, quality, and affordability of health services to urban versus rural residents. Affordability is understood not as an additional payment to focused specialists, which is one of the "findings" of modern healthcare modernization but as a solution to "paramedical problems": road and transport infrastructure, barrier-free environment, accomodation during examination and treatment, integration with social services and more.

2. Staffing the health-care system: The main problem is the lack of qualified personnel. 580,431 physicians and 1,287,659 health workers with secondary vocational-education work at medical organizations of the Russian Ministry of Health were recorded as of January 1, 2015. The ratio of the number of doctors and nurses in the Russian Federation in 2014 amounted to 1: 2.3, which corresponds to the figure of the Program [8]. The provision of the Russian population with doctors is 40.3 and with nurses-100.0 (per 10,000 people) [9].

According to the Accounting Chamber, 90,000 medical employees were dismissed through Russia (Table 3). The largest redundancies were observed in clinical specialties-over 19,000 people (except doctors working at the Crimean Federal District medical institutions).

The health-care optimization resulted in decrease in service affordability and in worse efficiency of state and municipal organizations, primarily expressed in growth by $3.7 \%$ in the death number at hospitals, increase by $2.6 \%$ of in-hospital patients' mortality, deterioration in the quality of population life.

According to the Accounts Chamber audit [11], 55,000 doctors and 88,000 nurses are currently required. Thus, the implemented measures on the reduction of the number of care workers do not correspond to the actual situation in the regions and to the current needs. Measures taken to increase the number of personnel are required to be analyzed and probably adjusted.

The second major problem-is a problem in the personnel policy (salary level, working conditions). Overall, the public sector employees' salary increased in 2014 in absolute terms. According to Rosstat [12], the average salary of doctors increased by 4,000 rubles; average salary of medical (pharmaceutical) staff, by 2,200 rubles; average salary of nurses, by 1.8 thousand rubles in 2014 compared to 2013 .

However, the health workers' salary is greatly affected by a high percentage of internal combination, which is a quarter of the total

\begin{tabular}{|c|c|c|c|}
\hline $\begin{array}{c}\text { Doctors and health-care employees } \\
\text { with higher medical (pharmaceu- } \\
\text { tical) or other higher education } \\
\text { providing health care services }\end{array}$ & $\mathbf{2 0 1 3}$ & $\mathbf{2 0 1 4}$ & Reduction \\
\hline $\begin{array}{c}\text { Nursing (pharmaceutical) staff } \\
\text { (personnel ensuring conditions for } \\
\text { the health-service provision) }\end{array}$ & $1,442,157$ & $1,401,660$ & $-40,498,939$ \\
\hline $\begin{array}{c}\text { Junior medical staff (personnel } \\
\text { ensuring conditions for the } \\
\text { health-service provision) }\end{array}$ & 687,139 & 650,464 & $-36,675$ \\
\hline
\end{tabular}

Table 3: The number of health workers according to the Federal State Statistics Service (a federal statistical survey ZP-zdrav form) for 2013-2014 [10] 
Citation: Kalmikov NN, Rekhtina NV (2016) The Health-Care System Issues and Prospects in the Russian Federation. Biol Med (Aligarh) 8(4): 301. doi:10.4172/0974-8369.1000301.

Page 4 of 6

payroll. This means that the increase in average wages of health workers is caused not by an actual increased salary but by increased load per employee, when a physician works for 12 or more instead of 8 hours [11].

With the increase in wages, interregional differentiation of care employees' salary levels decreased as well. At the end of 2014, the differentiation in the ratio of doctors' average wages to average wages in the Russian Federation decreased from 3.2 to 1.6 times in 2012, of nurses, from 2.5 to 1.6 times [13].

If we compare a doctor's wage in Russia to a doctor's wage in new EU members, the latter's salary is 1.5-2.5 times as more as an average wage in these countries [14].

The third important issue is poor quality and degraded training. The expert survey conducted (Note 3 ) showed that poor training and insufficient qualification of medical personnel resulted in poor quality of care services. Insufficient qualification of medical personnel is expressed in negative indicators of the care quality. For example, the mortality of breast cancer patients, in-hospital mortality rate, and the coefficient of patients who got infectious complications in hospitals in the Russian Federation is twice as much as an average indicator in OECD countries [14].

The fourth important issue-movement of professionals into the private sector. Experts note a tendency towards the movement of professionals into the private sector. Russian population has begun to use paid services more often; the scope of paid medical service grew by $24.2 \%$ in 2014 compared to 2013 . According to an auditor of the Accounting Chamber [14], the growth of paid medical services combined with lower affordability of health care for the population may indicate a substitution of free medical care with a chargeable one.

3. Experts stated the following problematic aspects of the health system (Figure 4): poor quality of services and medication (8.1); commercialization of the health-care industry, including corruption (5.8); unavailability of certain services and medication (5.2); ambiguous attitude of the people (patients) to modern medicine (lack of respect and culture) (5.2); poor provision of medical institutions with necessary

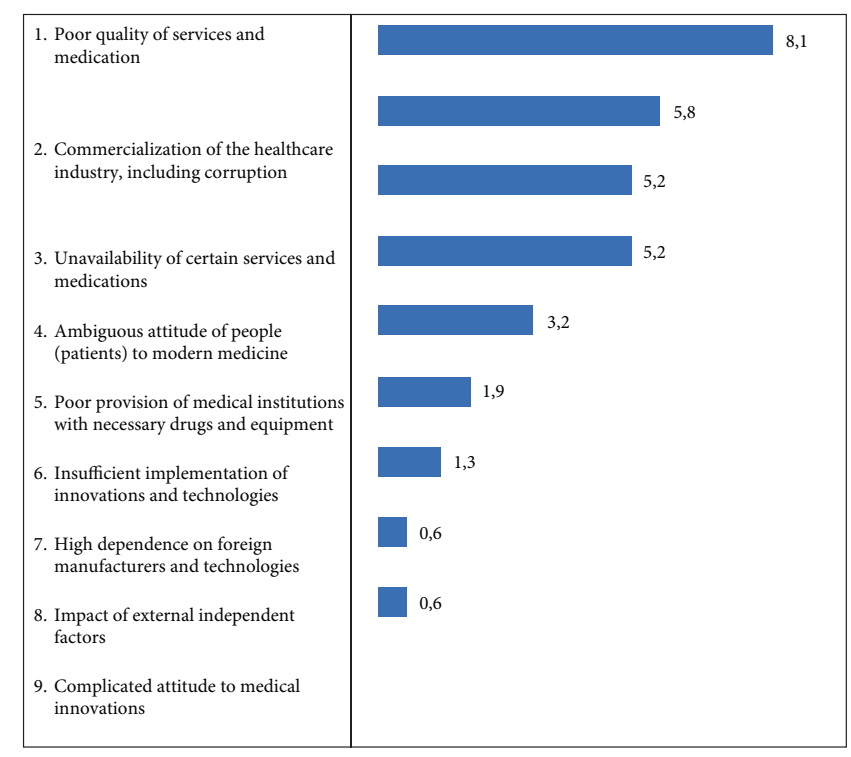

Figure 4: Problematic aspects of the health care system, \%

\begin{tabular}{|c|c|c|c|}
\hline & Score & SD & $\mathbf{N}$ \\
\hline Protection of maternal and child health & 2.9699 & 0.9842 & 133 \\
\hline $\begin{array}{l}\text { Improving emergency care, including emergency } \\
\text { specialized care and medical evacuation }\end{array}$ & 2.7895 & 0.9133 & 133 \\
\hline $\begin{array}{l}\text { Development and implementation of innovative } \\
\text { methods of disease diagnostics }\end{array}$ & 2.686 & 1.1299 & 86 \\
\hline Industry development management & 2.6846 & 1.0420 & 130 \\
\hline $\begin{array}{l}\text { Medical and sanitary provision of certain } \\
\text { categories of people }\end{array}$ & 2.6154 & 0.9097 & 130 \\
\hline $\begin{array}{l}\text { Improving specialized medical care, including } \\
\text { high-tech care }\end{array}$ & 2.6119 & 0.9251 & 134 \\
\hline Development of primary health care & 2.6119 & 0.9332 & 134 \\
\hline $\begin{array}{l}\text { Examination and supervisory functions in health } \\
\text { protection }\end{array}$ & 2.6098 & 0.8929 & 123 \\
\hline $\begin{array}{c}\text { Promotion of international contacts in health } \\
\text { protection }\end{array}$ & 2.4344 & 0.9270 & 122 \\
\hline $\begin{array}{c}\text { Development of medical rehabilitation and spa } \\
\text { treatment }\end{array}$ & 2.3985 & 0.9609 & 133 \\
\hline $\begin{array}{l}\text { Development and implementation of innovative } \\
\text { methods of prophylaxis and treatment, as well as } \\
\text { personalized medicine principles }\end{array}$ & 2.2835 & 0.8442 & 127 \\
\hline $\begin{array}{l}\text { Disease prophylaxis and promotion of healthy } \\
\text { lifestyle }\end{array}$ & 2.2481 & 0.8739 & 133 \\
\hline Palliative care to population & 2.2000 & 0.8799 & 125 \\
\hline $\begin{array}{l}\text { Staffing the health care system in accordance } \\
\text { with modern demand }\end{array}$ & 2.1729 & 0.8212 & 133 \\
\hline $\begin{array}{c}\text { Introduction of the personalized medicine } \\
\text { principles }\end{array}$ & 2.1680 & 0.8302 & 125 \\
\hline
\end{tabular}

Table 4: Evaluation of effectiveness of measures on the state program "The health-care development" implementation

drugs and equipment (3.2); insufficient implementation of innovations and technologies (1.9); high dependence on foreign manufacturers and technologies (1.3); impact of external independent factors (0.6); complicated attitude to medical innovations (0.6); poor demand for medical care $(0.3)$; inefficient time management in providing medical service (0.3).

According to experts, the most effective measures for implementation of the Program [8] are aimed at protecting maternal and child health; improving emergency care, including emergency specialized medical care and medical evacuation; and development and implementation of innovative methods of disease diagnostics. Implementation of the personalized medicine principles, staffing the health-care system in accordance with modern demands, and providing the the population with palliative care are considered to be the least effective measures (Table 4). These areas should be the main focus (get more attention) while planning the Program's further implementation.

\section{Prospects for medicine development}

The demand for new life quality requires diagnostic and treatment methods based on personalized medicine principles, reliable noninvasive express technologies of monitoring at home, remote methods of medical-care provision, and characterized by prophylaxis, safety, high efficiency.

The key scientific and technological areas making products competitive (works, services) in health care primarily include:

- technological development of personalized health care allowing to individualize diagnostic processes, to provide targeted medical and other therapeutic effects, which will greatly enhance treatment benefits and reduce treatment costs; 
Citation: Kalmikov NN, Rekhtina NV (2016) The Health-Care System Issues and Prospects in the Russian Federation. Biol Med (Aligarh) 8(4): 301. doi:10.4172/0974-8369.1000301.

Page 5 of 6

- distribution of "smart" drugs with efficacy modulated by their environment or by specific drug ingredients aimed at an increase in efficiency, specificity, and localization accuracy;

- application of noninvasive ("no surgery," "low-trauma") diagnostics methods;

- creation of systems for monitoring and continuous surveillance of certain groups of patients, and/or certain groups of diagnoses to provide proper assistance in critical conditions;

- provision of palliative care to the population of Russian Federation.

The above measures will ensure a mobilization scenario for the development of national health care and will efficiently reduce morbidity and mortality from cancer, cardiovascular diseases, and diseases associated with the metabolic process disorders (diabetes, obesity, etc.).

This scenario of competitive development involves changing the existing management model, attracting private investment, and developing competitive principles for all service providers and industry resources. The scheduled tendencies toward import substitution on the service markets require changes of regional approaches to the government procurement placement.

A competitive model of public-private health is associated with investment in projects on development of high technology and human capital with return of investment, far beyond the current market's medium-term limits. The main barriers are caused by a deficiency of competitive professional staff at the corporate and public governance and inefficient mechanisms of effort coordination.

Experts offered (Note 3) measures to improve the quality and/or affordability of medical services for the population:

1. Transition of medical workers to an "effective contract," creation of incentives for medical staff (49\%).

2. Development of fundamental science in evidence-based medicine, biostatistics, pharmacoeconomics, economic analysis involving experts and professors from other countries (44\%).

3. Revision of the system of indicators reflecting the health state (life expectancy, mortality rates range with the indicators of doctors' average wages) (43\%).

4. Development of spa treatment systems, including one for children (42\%).

5. Development of evidence-based methodology for evaluation of spending effectiveness (34\%).

6. Creation of an independent expertise system for making decisions related to budget expenditures (41\%).

7. Development of business and investment programs aimed at developing the health sector (40\%).

8. Conversion of clinical examination into effective programs for prophylaxis of noninfectious and infectious diseases (40\%).

9. Improving the mechanisms of reimbursement and copayments of drug costs (39\%).

10. Ensuring proper supervision for drug production and circulation (35\%).

11. Inclusion into the system of indicators those values which are used by the WHO in their rating (30\%).

12. Others $(6.3 \%)$ :

- Integration of the health insurance mechanism (0.7\%);

- State control $(0.7 \%)$;

- Sufficient financial support (0.7\%);
- Avoidance of overload and overworking by physicians (0.7\%);

- Medicine focus upon training of highly qualified medical specialists, rather than equipment purchase and revision of the system of interaction between the compulsory health insurance system and health care institutions (0.7\%);

- Revision of industry's time limits for the examination of a patient $(0.7 \%)$;

- Increasing the prestige and improving the arrangement of outpatient care $(0.7 \%)$

- Tackling the problem of shortage of qualified health workers $(0.7 \%)$;

- Increasing the state financing of the industry $(0.7 \%)$;

- Improving top-management skills (0.7\%).

In conclusion, we can say that there are both challenges in and potential ways of increasing health-care system efficiency. The experts' opinions show quite a wide range of priority areas to focus upon while making police decisions in the field of health-care development. All these areas should be interconnected and accompanied by financial, economic, medical, managerial mechanisms and tools, allowing them to form a systematic approach for the development and modernization of the health-care system in the Russian Federation.

\section{References}

1. Kotova YN (2004) "Evaluation of the regional health system efficiency." The author's abstract, PhD in Economics, Ryazan, p. 24.

2. Banin SA (2012) The Russian Health: funding issues and solutions. Bull Tomsk State Univ 3(19): 112-117.

3. Electronic resource: www.bloomberg.com/visual-data/best-and-worst//mostefficient-health-care-2014-countries (date of reference March 8, 2015).

4. Business newspaper Vzglyad [electronic resource]: www.vz.ru/ news/2014/6/18/691705.html (date of reference July 28, 2015).

5. The Atlantic-News and analysis on politics [electronic resource] www theatlantic.com (date of reference July 28, 2015).

6. Robin Hanson, "Cut Medicine in Half," Cato Unbound, Date Views September 10, 2007, www-cato-unbound.org/2007/09/10/robin-hanson/cut-medicine-in-half

7. Sheiman IM, Shishkin SV (2009) The Russian Health Care: New Challenges and New Tasks: Report of the State University-Higher School of Economics: $X$ International Scientific Conference of the State University Higher School of Economics on the economy and society development problems (Moscow, April 7-9, 2009). Moscow: Publishing House at the State University Higher School of Economics, p. 66.

8. The Russian Federation State program "The health care development" www. rosminzdrav.ru/ministry/programms/health/info (date of reference March 8, 2015).

9. Kagramanyan IN (2014) On the staffing for the health care system of the Russian Federation. Education and training of medical personnel, 277-280.

10. Russian Statistical Yearbook-2014. www.gks.ru/bgd/regl/b14_13/Main.htm (date of reference March 8, 2015).

11. The Accounting Chamber audit report "On the optimization of health, culture education and social services" www.ach.gov.ru/press center/news/21297 (date of reference March 8, 2015).

12. Online resource: Federal State Statistics Service www.gks.ru/wps/wcm/ connect/rosstat_main/rosstat/ru/statistics/wages/labour_costs/ (date of reference March 8, 2015).

13. The report of the Ministry of Health of the Russian Federation "On the outcome of the Russian Ministry of Health in 2014 and tasks for 2015," Moscow, April 2015 (date of reference 03.08.2015).

14. Ulumbekova GE (2012) The Russian Federation health care system: results, problems, challenges and solutions. Roszdravnadzor Bull 2: 33-38.

15. The study "Health: situation, challenges and opportunities (including, the state program)" conducted by RANEPA employees, research director-Doctor of Philosophy in Social Sciences Kalmykov. The survey among 143 experts was conducted in March 2015. 
Citation: Kalmikov NN, Rekhtina NV (2016) The Health-Care System Issues and Prospects in the Russian Federation. Biol Med (Aligarh) 8(4): 301. doi:10.4172/0974-8369.1000301.

Page 6 of 6

16. Electronic resource: RANEPA experts' survey online page on www.publicserv.ru (date of reference April 29, 2015).

17. Rosstat database: www.gks.ru/wps/wcm/connect/rosstat/rosstatsite/main (date of reference July 29, 2015).

18. The concept of the long-term social and economic development of the Russian Federation till 2020-economy.gov.ru/minec/activity/sections/ strategicPlanning/concept/indexdocs (date of reference March 8, 2015).

\section{Notes}

1. This figure probably did not attract public attention as it was partially compensated by the migration exchange about $6,400,000$ people.

2. Requirements for experts: reference from other experts, professional experience in the field of study for over 5 years, applied experience on the research subject or scientific works (publications, monographs, articles, etc.) participation in scientific conferences/seminars/forums, attendance of sessions and meetings held by the authorities. The selection of experts to participate in servey was carried out by the snowball sampling —only by recommendations of reliable experts' and leaders' for each interviewed expert. The snowbal sampling method is the best option in this case, since if you get into a sertain professional environment through expert's recommendation you are more likely to find other people conforming to similar requirements.

Expert makeup.
The main occupation: representatives of research organizations $(60 \%)$ including chiefs or deputies (18\%), representatives of public authorities $(32 \%)$ including $18 \%$ of chiefs or deputies, business representatives $(3 \%)$, physicians and head physicians (5\%).

We used the following methods of quality control: control over refilling of questionnaires from one PC, exception from the analysis of questionnaires completed too quickly (time control cycle), control over answers to "testing" questions, an individual check of each questionnaire on suspicious responses to open questions. Random telephone survey of experts to verify their participation in the expert online survey (however the questionnaire completion was anonymous).

3. The data of the social survey conducted by RANEPA expert analytical center 2015 .

4. LE-the number of years an individual from a hypothetical generation is expected to live provided that throughout the whole life of this generation a mortality rate at all ages remains the same as in the year which this indicator was calculated for.

5. CDR-the number of deaths of all causes per one thousand people.

6. SDR—simple average of age mortality rates by age group shares in the standard population. A standardized mortality rate is nothing but the mathematic expectation of discrete random variable with values equal to the age-specific mortality rates. The respective shares (relative frequencies) of the standard population serve as variables. 